\title{
»Barth erzog mich zum Atheisten«
}

\author{
Walser und Dürrenmatt als Barth-Leser - \\ ein kleiner Vergleich
}

Pierre Bühler

Als ich Martin Walsers Büchlein Über Rechtfertigung, eine Versuchung las, ist mir der in der Überschrift zitierte Satz aus Dürrenmatts Turmbau von 1990 öfters in den Sinn gekommen. ${ }^{1}$

Der Kontrast ist nämlich sehr markant. Bei Walser wird Karl Barths Römerbrief in Anspruch genommen für die Auseinandersetzung mit einem heute grassierenden, selbstzufriedenen Atheismus. Der Autor spielt auf eine Fernsehsendung an, in der zur Frage nach Gott "das gewöhnliche Hin und Her zwischen Gegnern und Befürwortern" stattfindet. Der wortführende Atheist »bot ein andauerndes Schmunzeln. Ein unangreifbares, ein allem überlegenes Schmunzeln«. Und Moderator und Regie sind auf seiner Seite, so dass der Befürworter des Gottesglaubens chancenlos ist. "Wie kann man bloss noch an Gott glauben! « ${ }^{2}$ Diese Beschreibung der Fernsehsituation führt Walser zum für sein ganzes Büchlein tragenden Grundgedanken: „Wer sagt, es gebe Gott nicht, und nicht dazusagen kann, dass Gott fehlt und wie er fehlt, der hat keine Ahnung. $\|^{3}$

Im Laufe der Schrift stehen deshalb Barths Römerbrief und der zu bekämpfende Atheismus öfters einander gegenüber. So etwa, wenn ein Barth-Zitat an die Fernsehsendung zurückerinnert:

"Als der unbekannte Gott wird Gott erkannt: [...] als der, an den man nur ohne Hoffnung auf Hoffnung hin glauben kann. Wenn ich heute diesen Satz lese, sehe ich den in unerreichbarer Selbstzufriedenheit schmunzelnden Atheisten vor mir. ${ }^{4}$

Wie kann nun Dürrenmatt dazu kommen, von Barth genau das Umgekehrte zu sagen: Barth nicht als Bekämpfer von Atheismus,

1 F. Dürrenmatt, Turmbau. Stoffe IV-IX, in: Ders., Werkausgabe in siebenunddreissig Bänden (im weiteren abgekürzt:WA), Bd. 29, Zürich 1998, 208.

2 Alle Zitate des Abschnittes: M. Walser, Über Rechtfertigung, eine Versuchung, Reinbek bei Hamburg 2012, 33.

3 Ebd.

4 Ebd., 52 (Hervorhebungen und Auslassung von M.W.). Diese Gegenüberstellung kann Walser auch so zum Ausdruck bringen, dass er ein Seminar zu Nietzsches Also sprach Zarathustra und Barths Römerbrief konzipiert (vgl. ebd., 58ff). 
sondern als Erzieher zum Atheismus? Dieser Unterschied erstaunt umso mehr, als bei beiden Schriftstellern zunächst eine vergleichbar enthusiastische Rezeption von Barths Römerbrief zu beobachten ist, bei Walser in Verbindung mit der besprochenen Schrift, also spät, bei Dürrenmatt hingegen in seiner frühen Schaffensphase, in der unmittelbaren Nachkriegszeit. ${ }^{5}$ In seinen autobiographischen Rückblicken erwähnt Dürrenmatt als wichtige Einflüsse neben Kierkegaard immer auch Barths Römerbrief: "Ich war von seinem Römerbrief fasziniert«, heisst es 1990. ${ }^{6}$ Das frühe Theaterstück Der Blinde setzt sich kritisch mit Barths Glaubensauffassung auseinander, und so findet denn auch anlässlich der Aufführung in Basel ein Treffen zwischen Barth und Dürrenmatt statt ("im Salon einer reichen Baslerin «").

Warum verwandelte sich bei Dürrenmatt diese frühe Faszination in die spätere Kritik? Die soeben zitierte Stelle könnte einen Hinweis geben. Es heisst dort, wenn man den ganzen Satz zitiert: ॥Ich war von seinem Römerbrief fasziniert, später von seiner Kirchlichen Dogmatik, in der ich auch heute noch lese. $\|^{8}$ Barth schenkte Dürrenmatt auf dessen Wunsch seine Dogmatik mit einer persönlichen Widmung im ersten Band, die folgendermassen lautet: »Der Dichter will den Theologen lesen? / Seine Freude darüber bezeugt der Verfasser dieser 10 (+ ) Bände! / Karl Barth«. Und so hat Dürrenmatt in späteren Jahren regelmässig in Barths Dogmatik gelesen und sich kritisch mit diesem späteren Barth auseinandergesetzt. Meiner Ansicht nach lässt sich dabei beobachten, wie Dürrenmatts zwei privilegierte Bezugsautoren, Kierkegaard und Barth, die früher ganz eng zusammengehörten, in der späteren Beurteilung immer mehr auseinandergeraten.

Aufgrund von Lektüren Kierkegaards in den 1970er Jahren gerät Dürrenmatt immer mehr in dessen Nähe und nimmt Abstand von Barth, und zwar an einer Stelle, die für Barths Verhältnis zu Kierkegaard auch bereits strittig war, nämlich der Betonung der Subjektivität des Glaubens. Das zeigt sich bereits im Essay über Israel: Da bezeichnet sich Dürrenmatt als »ein sehr merkwürdiger Protestant,

5 Für das Weitere, vgl. P. Rusterholz, Christliches Paradox als Skandalon und Korrektiv der Nachkriegskultur nach 1945: F. Dürrenmatt/K. Barth, in: N. Bakshi/D. Kemper/I. Bäcker (Hg.), Religiöse Thematiken in den deutschsprachigen Literaturen der Nachkriegszeit (1945-1955), München 2013, 73-89.

6 Dürrenmatt, Turmbau, WA 29, 192.

7 Ebd.

8 Ebd.Vgl. auch F. Dürrenmatt, Über Toleranz, 1977, Rede anlässlich derVerleihung der Buber-Rosenzweig-Medaille am 6. März 1977, WA 33, 125-149, 128: „Karl Barths Römerbrief war für mich ein revolutionäres Buch, seine Dogmatik, in der ich oft lese, ein mathematisches Meisterwerk.» 
einer, der jede sichtbare Kirche ablehnt, einer, der seinen Glauben für etwas Subjektives hält, für einen Glauben, den jederVersuch, ihn objektiv auszudrücken, verfälscht, einer, dem das subjektive Denken wichtiger als das objektive Denken ist. " $"$ In derselben Schrift erzählt er später, was ihm plötzlich einleuchtete, als er vor seiner Mutter auf dem Sterbebett steht: Der Wüstengott »lässt sich nur erleben in der Erschütterung, so dass denn Glauben nicht ein Für-wahrHalten, sondern ein Erschüttertsein bedeutet ${ }^{10}{ }^{10}$ In seiner Rede über Toleranz vom März 1977 wird er, von Kierkegaards Grundsatz der Wahrheit als Subjektivität ausgehend, im jüdisch-christlichen Dialog von einer existentiellen Toleranz sprechen können, während sich für ihn an Barths Kirchlicher Dogmatik zeigt, dass eine der Hauptwurzeln des Antisemitismus im Christentum liegt. ${ }^{11}$

Diese kritische Auseinandersetzung kulminiert in eine Art Abrechnung in Turmbau, in der vieles grobschlächtig und pauschal formuliert wird, aber doch gewisse polemische Pointen nicht verfehlt sind. Barths analytische Denkkraft bewundernd, sagt Dürrenmatt: "Seine Dogmatik transponiert Hegel in die Bibel wie Thomas von Aquin Aristoteles. ${ }^{12}$ In diesem Kontext folgt ein langes Zitat aus der Kirchlichen Dogmatik:

"Wahre Gotteserkenntnis ist unangegriffen und unangreifbar, ohne Sorgen und Zweifel. Solche wahre Gotteserkenntnis ist aber die und nur die, die sich in der Bindung an Gottes Wort vollzieht. Alles Entweichen aus der Bindung des Wortes Gottes bedeutet den Übergang zu den falschen Göttern, zu den NichtGöttern - was sich darin zeigen wird, dass es unweigerlich die Unsicherheit der Gotteserkenntnis über sich selbst und also den Zweifel nach sich zieht. «13

Dieses Zitat wird mit dem lapidaren Kommentar quittiert: „Wer so redet, glaubt sich im Besitz der Wahrheit « ${ }^{14}$. Interessant ist, dass Dürrenmatt im Kommentar zu seinen Papstbildern ein ganz ähnliches Urteil formuliert: Der Papst ist das Sinnbild des Theologischen und damit des Rechthaberischen, des Glaubens, im Besitze der Wahrheit zu sein." Demgegenüber steht in Kierkegaardscher Manier: "Das

9 F. Dürrenmatt, Zusammenhänge. Essay über Israel. Eine Konzeption, 1975, WA 35, 27.

${ }^{10}$ Ebd., 127.

${ }^{11}$ Dürrenmatt, Über Toleranz, 125-149. Zu Barth vor allem $139 f$.

12 Dürrenmatt, Turmbau, 7 (für die ganze Auseinandersetzung mit Barth, und damit auch mit dem Christentum überhaupt, vgl. 192-207).

${ }_{13}$ Dürrenmatt zitiert aus K. Barth, KD II, 1, $\ 25,5 \mathrm{f}$ (Zitierfehler wurden berichtigt).

14 Ebd. 
Christentum, das sich nicht als Skandalon begreift, hat keine Berechtigung mehr. ${ }^{15}$

So könnte man sagen, dass in der Kirchlichen Dogmatik die Theologie in dieser sehr negativen Konnotation den Glauben zu ersticken droht: »In der Theologie vollzieht der Glaube Selbstmord: Er glaubt zu wissen. ${ }^{16}$ In sehr subtiler Weise zeigt Dürrenmatt diese Gefahr bei Barths Versuch, das Nichtige theologisch in den Griff zu bekommen, auf. ${ }^{17}$ Demgegenüber betont Dürrenmatt im Sinne der Subjektivität des Glaubens, es bleibe ihm nichts anderes übrig,

»als mein eigenes Floss zu besteigen, um so mehr, als ich mit ihm schon längst in diesem Ozean dahintreibe, ohne Ruder und Segel, jenseits jeder Sichtweite eines Hafens, ja einer Küste; allein von der Vorstellungskraft in die Bereiche des rein Vorstellbaren, des Möglichen, des Wahrscheinlichen, des Unvorstellbaren, des nur noch Ahnbaren getrieben, hinein in die Welt des Grotesken und des Paradoxen. ${ }^{18}$

Diese Position versucht Dürrenmatt erkenntnistheoretisch zu explizieren, indem er vom englischen Wissenschaftstheoretiker Arthur S. Eddington die Unterscheidung zwischen strukturellem und sympathetischem Wissen aufgreift. ${ }^{19}$ Das strukturelle Wissen ist ein mathematisch ausdrückbares Wissen, das den erforschbaren Strukturen gilt, "während das sympathetische Wissen ein Verstehen ist ${ }^{20}{ }^{20}$ Das führt Dürrenmatt dazu, die Frage, ob Gott existiere, für sinnlos zu halten:

»zählt die Umwandlung von Materie in Strahlung im Sonneninnern, in den Sternen, durch die Noven und Supernoven, zum strukturellen Wissen, gibt es keine metaphysische Supernova, die auf Gott hinweist. Gott ist ein sympathetisches Wort, ich verstehe es zwar, wenn es einer ausspricht, aber ich weiss nicht, was er sich dabei vorstellt, es wird nie gelingen, es in eine objektive Erkenntnis zu verwandeln. Gott ist etwas Subjektives «. ${ }^{21}$

Um Glaube zu bleiben, braucht der Glaube keine Metaphysik. Wenn Kant die Unbeweisbarkeit Gottes bewiesen hat, "wieviel un-

\footnotetext{
${ }^{15}$ Beide Zitate: F. Dürrenmatt, Persönliche Anmerkung zu meinen Bildern und Zeichnungen, WA 32, 205.

${ }^{16}$ Dürrenmatt, Turmbau, 205.

17 Ebd., $196 f$.

18 Ebd., 206.

${ }^{19}$ Ebd., 201ff.

${ }^{20}$ Ebd., 201.

${ }^{21}$ Ebd., 202f.
} 
beweisbarer müssen denn auch all die Schlüsse sein, die aus diesem Unbeweisbaren gezogen werden «. ${ }^{22}$ Barths Lehre von Gott in der Kirchlichen Dogmatik jedoch umfasst zwei dicke Bände, und "wäre das Kleingedruckte, Interessantere, gross gedruckt, wären es fünf, ein Riesenwerk derVorstellungskraft «. ${ }^{23}$ Die massive Entfaltung des christlichen Glaubens in der Kirchlichen Dogmatik wird Dürrenmatt immer mehr zum Problem, weil dem Zweifel immer weniger Platz gewährt wird. In Turmbau wird das Christentum zu einer immer schwierigeren Denkmaschinerie, durch eine vergröbernde Relektüre des Apostels Paulus, aber nicht zuletzt auch durch das Hadern mit Barths "Riesenwerk der Vorstellungskraft». Und so kommt es, von Barth her, zur grundsätzlichen Auseinandersetzung mit dem Christentum selbst: »Barth erzog mich zum Atheisten, und die ersten Ratten sind auch erschienen. $\mathbb{1}^{24}$

Kommen wir zum Schluss. Es wäre interessant zu schauen, was aus Walsers Barth-Rezeption würde, wenn er wie Dürrenmatt zu einem Leser der Kirchlichen Dogmatik würde! Auf jeden Fall fällt auf, dass er den Römerbrief recht unmittelbar ins Spiel bringt, im Gegensatz zu Dürrenmatt, der von Kierkegaard und von Eddington her reflektiert, unter welchen Bedingungen es überhaupt Sinn macht, von Gott zu reden. Deshalb ist sein Atheismus sicher auch kein selbstzufriedener, schmunzelnder Atheismus. Es würde sonst nicht heissen: "und die ersten Ratten sind auch erschienen«. Vielleicht ist der Atheist Dürrenmatt nur eine Radikalisierung des merkwürdigen Protestanten, der gegen eine zu päpstliche Dogmatik mit dem Kopenhagener Sokrates in Sachen Gott die Subjektivität der Wahrheit einschärft...

- Pierre Bühler ist ordentlicher Professor für Systematische Theologie, insbes. Hermeneutik und Fundamentaltheologie an der Theologischen Fakultät der Universität Zürich und Leiter des dortigen Instituts für Hermeneutik und Religionsphilosophie.

${ }^{22}$ Ebd., 204.

${ }^{23}$ Ebd., 205.

${ }^{24}$ Ebd., 208. 